\title{
Co-registration of nuclear scintigraphic and magnetic resonance data of the equine foot: A multi-modality imaging 'proof of principle' study
}

\author{
Carolyne A. Tranquille, Julie A. Breingan, Simon N. Collins, Sue J. Dyson, Steve Bloomer, Susan Ellam, David I. Wimpenny, Jonathan \\ Hall and Rachel C. Murray \\ Centre for Equine Studies, Animal Health Trust, Lanwades Park, Kentford, Newmarket, Suffolk, England
}

\begin{abstract}
Summary
Three-dimensional (3D) multi-modality imaging (MMI) is frequently used in human medicine but its use in equine diagnostic imaging has yet to be validated. In a proof of principle manner, this study aimed to evaluate 3D MMl co-registration of magnetic resonance (MR) and scintigraphic data for the assessment of equine foot injury. A multi-compartment equine foot phantom was designed and constructed using the Stereolithography Additive Manufacturing process. Images were obtained by MR imaging and by scintigraphy using different copper sulphate concentrations $\left(\mathrm{CuSO}_{4}\right)$ (for MR imaging) or radiopharmaceutical concentrations (for scintigraphy) respectively, which were introduced into the compartments of the foot phantom to mimic the normal limb appearance for each image modality. Lesions at specific locations were simulated by introducing increased concentrations of $\mathrm{CuSO}_{4}$ or radiopharmaceutical into the appropriate compartments. 3D scintigraphic data was obtained by rotating the phantom through $360^{\circ}$ with dynamic acquisitions performed every $3^{\circ}$. The MR and scintigraphy data were co-registered using proprietary software. MR image assessment showed the individual compartments of the phantom, and the location of a simulated lesion. The presence of increased radiopharmaceutical concentration was clear on scintigraphic images, but anatomical resolution was less clear than MR images. Accurate detection and localisation of simulated lesions were best with 3D coregisteration of the MR and scintigraphic images. In the future, 3D co-registration of scintigraphic and MR images may prove clinically useful to localise and differentiate between active and inactive injury. Issues relating to the practical implementation of 3D MMI in the standing sedated horse are discussed.
\end{abstract}

Keywords: horse / multi-modality imaging / scintigraphy / magnetic resonance imaging / diagnostic imaging

Bildregistrierung von Daten aus der nuklearen Szintigraphie und Magnetresonanztomographie des Perdefußes: Eine multimodale bildgebende 'proof of principle' Studie

Die drei-dimensionale (3D) multi-modale Bildgebung wird in der Humanmedizin häufig angewandt, ihre Bedeutung in der equinen Bildgebung muss jedoch erst evaluiert werden. Ziel der Studie ist die Untersuchung der 3D multimodalen diagnostischen Bildregistrierung von Daten aus Szintigraphie und Magnetresonanztomographie (MRT) für die Beurteilung von Verletzungen der Pferdezehe. Mit Hilfe des stereolithographischen Manufakturprozesses wurde ein Multikompartment-Modell der Pferdezehe entworfen und hergestellt. Bildgebende Untersuchungen wurde mittels MRT und Szintigraphie durchgeführt. Um ein physiologisches Erscheinungsbild der Zehe für die jeweilige bildgebende Methode zu gewinnen wurden verschiedene Kupfersulfat- $\left(\mathrm{CuSO}_{4}\right)$ (für MRT) und radiopharmazeutische Konzentrationen (für Szintigraphie) in das Modell injiziert. Läsionen an spezifischen Lokalisationen wurden durch Injektion größerer Konzentrationen von $\mathrm{CuSO}_{4}$ oder Radiopharmazeutika in den verschiedenen Departments simuliert. Die 3D-Szintigraphie wurde durch Rotieren des Phantoms um 360 durchgeführt während alle 3 Grad die dynamische Datenerfassung erfolgte. Die gewonnen Daten aus MRT und Szintigraphie wurden mit Hilfe eines eigenen Softwareprogramms überlagert. Die MRT-Ergebnisse stellten die individuellen Departments des Phantoms und die Lokalisation der simulierten Läsion dar. Die Szintigraphie zeigte deutlich eine erhöhte radiopharmazeutische Konzentration an, jedoch war die anatomische Darstellung der Strukturen im Vergleich zu den MRT-Ergebnissen weniger deutlich. Eine akkurate Erkennung und Lokalisation der Läsionen erfolgte am besten mittels 3D-Bildüberlagerung von Daten aus der szintigraphischen und MRT Diagnostik. In Zukunft könnte sich die 3D-Bildüberlagerung von szintigraphischen und MRT Bildern als wertevolle Hilfe erweisen um zwischen aktiven und inaktiven Verletzungen zu unterscheiden. Die praktischen Aspekte der Anwendung von 3D multi-modaler bildgebender Diagnostik beim stehenden sedierten Pferd werden diskutiert.

Schlüsselwörter: Pferd / multi-modale bildgebende Diagnostik / Szintigraphie / Magnetresonanztomographie / bildgebende Diagnostik

\section{Introduction}

The accurate determination of the site of orthopaedic injury is a primary objective in lameness assessment. This poses a diagnostic challenge when evaluating foot pain in the horse as the foot has a complex three-dimensional anatomy, which is enclosed within the hoof capsule. In addition, active and inactive pathological abnormalities may co-exist (Murray et al. 2006, Rabba et al. 2011), therefore difficulties can be encountered in identifying the precise cause of lameness (Dyson 2002), with respect to accurately locating the anato- mical site, identifying the precise anatomical structures involved, and interpreting the relative significance of detected 'lesions' as they may, or may not be, the main cause of lameness. Hence, there is a need for enhanced diagnostic methods to improve the management of horses with foot pain.

Magnetic resonance (MR) imaging provides images of high anatomical definition in three dimensions, which enhances the ability to recognise structural abnormalities within bone and soft tissues compared with two-dimensional (2D) planar 
imaging (e.g., radiography). Different structures have varying signal intensities on different image sequences, so all sequences need to be assessed to determine whether an abnormality is potentially active or not (Murray and Werpy 2001, Dyson et al. 2011). Multiple MR 'abnormalities' are frequently detected in both lame and sound limbs (Dyson et al. 2003, Murray et al. 2006, Sherlock et al. 2007, Gonzalez et al. 2010, Dyson 2011, Dyson and Murray 2011). Some of the abnormalities may be active or inactive, and in the absence of physiological information (obtained from scintigraphic assessment), it can be difficult to determine the actual cause of lameness with certainty.

Nuclear scintigraphy evaluates the physiological activity within tissues, as indicated by increased radiopharmaceutical uptake (IRU). Increased radiopharmaceutical uptake may indicate the potential cause of pain in the foot. However this imaging technique has a number of inherent limitations: IRU may indicate physiological adaptation, IRU can persist at the site of injury due to on-going osteoblastic activity after the lameness has resolved, and lesions such as chronic ligament injury in mature horses, may be associated with variable radiopharmaceutical uptake (Dyson et al. 2006). Scintigraphy provides images of relatively low anatomical detail, which can make the identification of affected structures, adjacent to unaffected structures, difficult to assess. This may be the case when determining if IRU is associated with an enthesis, trabecular bone trauma or subchondral damage. This is particularly relevant within the foot where structures are small and difficult to differentiate without three-dimensional (3D) locations. For example, differentiating between abnormality within the spongiosa of the navicular bone, increased uptake at the origin of the distal sesamoidean impar ligament or within the ligament itself provides a challenge by scintigraphic assessment. In the distal phalanx, differentiating IRU associated with bone trauma of the palmar process of the distal phalanx, enthesious reaction at the insertion of the collateral ligament of the distal interphalangeal (DIP) joint or damage to the subchondral bone of the DIP joint can be difficult on 2D planar images.

To enhance the ability to diagnose the precise cause of pain/lameness in a foot, it may be useful to combine the anatomical information contained within MR data with the physiological information given by scintigraphy to provide further information on the current activity of detected lesions (Dyson and Murray 2007a and b, Nagy et al. 2008, Murray and Werpy 2011). Combining corresponding information from two or more imaging modalities is a process known as multi-modality imaging (MMI), or image fusion. In principle, $\mathrm{MMI}$ allows the determination of the precise location of active pathology with greater accuracy and certainty than single modality imaging alone.

Two-dimensional MMI has been used to co-register anatomical and physiological data in human medicine (Rueckert and Schnabel 2001, van der Born et al. 2001, Henriksen et al. 2009, Slomka and Baum 2009) and in the diagnosis of feline hyperthyroidism (Barthez et al. 2006). This technique has already been used in the Animal Health Trust (AHT) equine clinic where 2D planar scintigraphic images and have been fused with planar radiographs of the proximal phalanx (Bailey et al. 2007), the metacarpophalangeal and metatarsophalangeal joints (Biggi et al. 2009), the distal aspect of the carpus (Simon and Dyson 2012), the proximal aspect of the third metacarpal and metatarsal bones (Weekes et al. 2006) and the sacroiliac joints (Dyson et al, 2003) to determine which structures have IRU. The AHT has also used the technique to fuse lateral pool phase scintigraphic images and sagittal low-field standing MR images of the foot to show that the postulated IRU in the deep digital flexor tendon (DDFT) was actually in the DDFT region (Dyson 2012).

Three-dimensional MMI has been successfully implemented in several areas of human medicine to improve lesion localisation, including neurology (Pietrzyk et al. 1996, Cho et al. 2011 ), oncology (Lattanzi et al. 1997, van Dalen et al. 2007, Park et al. 2012), orthopaedics (Tsujikawa et al, 2010) and in surgical pre-planning (Kooy et al. 1997, Fei et al. 2002, Giesel et al. 2009). In human medicine, this technique enabled the detection and localisation of active injury sites with greater accuracy and certainty than with 2D MMI, and has established associations between physiology and anatomy that was not previously possible. However this technique may not be useful in all clinical cases because some horses with IRU on scintigraphic images at certain sites do not have signal alterations on MR images, and vice versa. For example, signal intensity changes within the collateral ligaments of the DIP joint on MR images are not always associated with IRU at their insertion on the distal phalanx (Dyson et al. 2004).

Despite 3D MMI being used successfully in human medicine, techniques need to be validated across species due to anatomical differences. This study aims to prove that co-registration of equine MR and scintigraphic images is possible and may assist in the diagnosis of lameness. This is especially important in areas such as the equine foot where small anatomical structures are adjacent to each other and need to be differentiated from each other during injury diagnosis. The objectives of this study were to:

- develop, and optimise, methods for image co-registration using a bespoke equine foot phantom

- assess, in a proof of principle manner, the ability of 3D MMI to localise compartmentalised areas of high radiopharmaceutical concentration within specific regions of clinical significance.

\section{Materials and methods}

For this proof of principle study it was not appropriate to use a live horse, so a chambered phantom of the equine foot was designed. The compartments were thin-walled, hollow and ported, so that they could be fluid-filled to replicate anatomical and physiological imaging of a horse's foot for MRI and nuclear scintigraphy.

\section{Phantom design and manufacture}

An eight component phantom of the equine foot was designed and manufactured using a Reverse Engineering approach. A computer model of the foot was generated from X-ray computed tomography (CT) data according to a method described in detail elsewhere (Collins et al. 2009). In summary, CT data was acquired from a cadaveric distal limb of a non- 
lame horse using a 16 detector CT scannera. The distal aspect of the limb was loaded in a purpose-designed jig to simulate the anatomical alignment of the limb during static weightbearing. Computed tomography projection data were reconstructed using both high resolution 'bone' optimised, and 'soft-tissue' optimised post processing algorithms (kernels). An eight component phantom was devised, in conjunction with clinical data input, to represent the major anatomical structures of the foot, the anatomical sites most often associated with palmar foot pain, and injury to the podotrochlear apparatus. The eight components of phantom were: the middle phalanx, the main body of the distal phalanx, the combined sites of insertion of the DDFT and distal sesamoidean impar ligament onto the distal phalanx, the medial and lateral palmar processes of the distal phalanx, the medial and lateral sites of insertion of the collateral ligaments of the DIP joint onto the distal phalanx and the navicular bone.

Localisation of these eight anatomical components of the phantom was achieved using Mimics Innovation Softwareb. Anatomical segmentation of the distal phalanx dermis and hoof was initially based on variation in radiopacity (thresholding) in either the bone optimised, or soft tissue optimised CT reconstructions. Further localisation of the key anatomical sites of injury was achieved manually, using 3-matic softwareb. Each component was designed as a thin-walled, hollow compartment using 3-matic softwareb, with ports leading to the external surface of the phantom. The ports allowed each component to be fluid-filled for image acquisition, either by MRI or nuclear scintigraphy.

The phantom was constructed by Additive Manufacturing. This technique enables objects of almost unlimited geometric complexity to be built up directly by the precise addition of material in layers (Wohlers 2009). This technique is particularly suited for the construction of complex free-form organic shapes, such as those encountered in the anatomy of the foot.

A stereolithography process was used to create a transparent phantom to help with filling of the individual compartments. In stereolithography each layer of the object is formed by scanning a UV laser across the surface of a vat containing an epoxy resin based photopolymer, which hardens where the laser strikes (Hopkinson et al. 2006). This process was repeated layer-upon-layer, in an additive manner, until the final object was complete. For this project DSM SOMOS 11110 watershed resinc was used, built in 125 micron layers using a SLA250/40 machined (Fig 1).

The individual compartments within the phantom were built separately (Fig 2a) and were then assembled within an inner shell to represent the hoof capsule (Fig 2b). To enable each individual compartment to be filled and emptied, two pipes ( $2 \mathrm{~mm}$ internal diameter) were added to each cell and these were connected to silicone tubing. A slow-setting, two-part, clear epoxy resin was poured into the space between the compartments to encapsulate the compartments and feed tubes (Fig 2c). The outer shell of the phantom was generated in nylon, using the Laser Sintering process where a fine powder was selectively heated to form the object. This was produced using polyamide 12 (EOSINT PA22e) powder on an EOS P100 laser sintering unite. To prevent leakage, valves were added to the end of each silicone tube (Fig 2d).
The middle phalanx and the main body of the distal phalanx were imaged as 'normal' for all tests to ensure images of clinical resemblance. The other compartments were imaged as normal or simulating injury, depending on the injury combination being tested. It was decided to test two common injury combinations, seen within the AHT caseload, on the final foot model:

- the navicular bone and insertion site of the DDFT and distal sesamoidean impar ligament

- the medial and lateral palmar processes and the insertion sites of the medial and lateral collateral ligaments of the DIP joint.

\section{$M R$ and scintigraphic image acquisition}

Optimisation of the acquisition protocol for both MR and scintigraphic images was achieved through use of test tubes to represent the signal intensities of normal tissue within each imaging modality. To optimise the acquisition protocol, tomo-

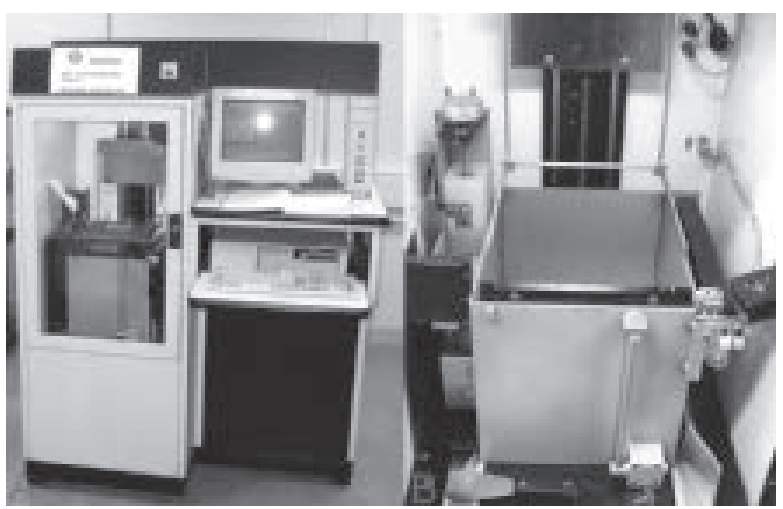

Fig 1 A-SLA250/40 machine used to create the phantom. B Inside the SLA250/40 machine

A: Die SLA250/40 Maschine wurde verwendet um das Phantom zu erstellen. B : Der Innenraum der SLA250740 Maschine

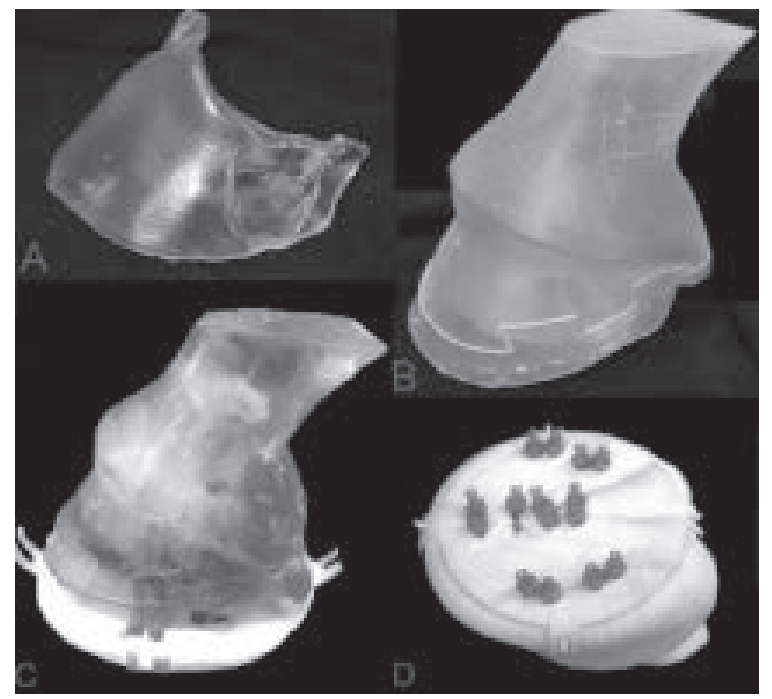

Fig 2 A-The internal compartment of the distal phalanx. B-The assembled inner shell. C-The inner shell and compartments after resin encapsulation. D-The outer nylon shell with the fill tube valves. A : Das innerste Department der distalen Phalanx. B: Die zusammengebaute innere Hülle. C: Die innere Hülle und die Departments nach der Verkleidung mit Harz. D: Die äußere Nylonhülle mit den Füllstützenventilen 
graphic acquisitions obtained with 10,20 and 30 seconds per projection were reconstructed both with and without resolution recovery. Resolution recovery techniques attempt to correct for the loss of spatial resolution during the iterative reconstruction process by modelling the effect of the collimator hole geometry on the acquired image. Resolution recovery can be used to improve image quality and can also be used to reduce the number of counts required to generate an image of the same or better quality than that obtained with conventional reconstruction. One of the obstacles hindering the application of conventional tomography to equine imaging has been the length of time needed to acquire sufficient counts in the images. Advanced reconstruction techniques are more tolerant of lower count images, allowing a shorter acquisition time, which makes equine tomography a practical possibility. This test was a quick check to see if acquisitions with short 10 second image duration gave acceptable resolution when reconstructed with resolution recovery.

Copper sulphate $\left(\mathrm{CuSO}_{4}\right)$, at 0.5 molar $(\mathrm{M})$ concentration was used in the phantom for MR image acquisition. A volu-

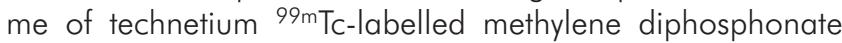
solution, with an activity of 10 mega becquerels $(\mathrm{MBq})$, was used for scintigraphic image acquisition. Each injury combination was imaged once with each imaging technique. Active injuries at specific anatomical locations were simulated by introducing a different $\mathrm{CuSO}_{4}$ concentration $(0.25 \mathrm{M})$, or increased activities of radiopharmaceutical (25 and $50 \mathrm{MBq}$ ) into the appropriate compartment. The middle phalanx had a volume of 58 millilitres ( $\mathrm{m} / \mathrm{s})$, the main body of the distal phalanx had a volume of $52 \mathrm{mls}$, the combined sites of insertion of the DDFT and distal sesamoidean impar ligament had a volume of $2 \mathrm{mls}$, the medial and lateral palmar processes of the distal phalanx had a volume of $2 \mathrm{mls}$ each, the medial and lateral sites of insertion of the collateral ligaments of the DIP joint onto the distal phalanx had a volume of $1 \mathrm{mls}$ each and the navicular bone had a volume of $4 \mathrm{mls}$. MR images were obtained by scanning the phantom using a human torso-phased array radiofrequency coil, positioned in the isocentre of a 1.5 Tesla GE Signa Echospeed MR imaging systemf and scanned with a standardised protocol (Fig 3a). Dorsal MR images were obtained using 3D T1 weighted spoiled gradient echo (SPGR) and 3D T2* weighted gradient echo scans. The sequences and parameters used were the same as those routinely used at the AHT during clinical scanning of equine patients (Table 1).

In order to obtain a tomographic image acquisition, the phantom was placed on a turntable and rotated in front of a static camera, as follows: a series of static planar scintigraphic images was obtained for the radiopharmaceutical distribution with a $500 \mathrm{~mm}$ circular-field of view GE gamma camera, with a low-energy, high-resolution collimatorg. In this way, a 3D tomographic volume (single photon emission computed tomography (SPECT) image) could be reconstructed. Images were obtained by rotating the phantom through $360^{\circ}$ with dynamic acquisitions $(128 \times 128 \times 16$ set) performed every $3^{\circ}$ ( $3 \times 5$ sec frames) (Fig 3b). With the detector in the same position, an acquisition was also obtained of a ${ }^{99 \mathrm{~m} T c}$ point source, by rotating a syringe containing radiopharmaceutical, which was off-set from the rotation axis by approximately $2 \mathrm{~cm}$, through $360^{\circ}$ with dynamic acquisitions $\left(64 \times 64 \times 16\right.$ set) performed every $5^{\circ}(1 \times 5 \mathrm{sec}$ frame $)$. This source point scan was used to check the centre of rotation of the rig to assist with SPECT reconstruction of the images. Due to the nature of the model and the location of the ports, MRI and scintigraphy were performed with the foot phantom placed upside down. The resultant images were rotated $180^{\circ}$ to represent the orientation of a 'standing' horse.

\section{SPECT Reconstruction of the Scintigraphy Projection Data}

The series of dynamic acquisitions was converted into a tomographic projection dataset. By combining up to three dynamic frames, each projection could represent five, 10, or 15s per frame to simulate different total acquisition times around the foot. The tomographic projection dataset was then reconstructed into a 3D SPECT volume using the proprietary HERMES HybridRecon Advanced Reconstruction softwareh. In summary, the reconstructed scintigraphic volume is a stack of transverse slices (oriented in a plane that is perpendicular to the axis of rotation of the camera), consisting of slices of $128 \times 128$ square pixels of $4.13 \times 4.13 \mathrm{~mm}$ and with a slice thickness (and separation) of $4.13 \mathrm{~mm}$ (i.e. the slices are adjacent to one another). Therefore, the volume consisted of cubic voxels of $4.13 \times 4.13 \times 4.13 \mathrm{~mm}$. This reconstruction software employs the latest resolution recovery algorithms to correct for the resolution loss, and resolution degradation with distance from the camera, brought about by the collimation process. This technique is key in optimising image quality whilst minimising acquisition time and/or injected dose, and which may make tomographic imaging of distal limbs in standing sedated horses a viable and practical possibility.

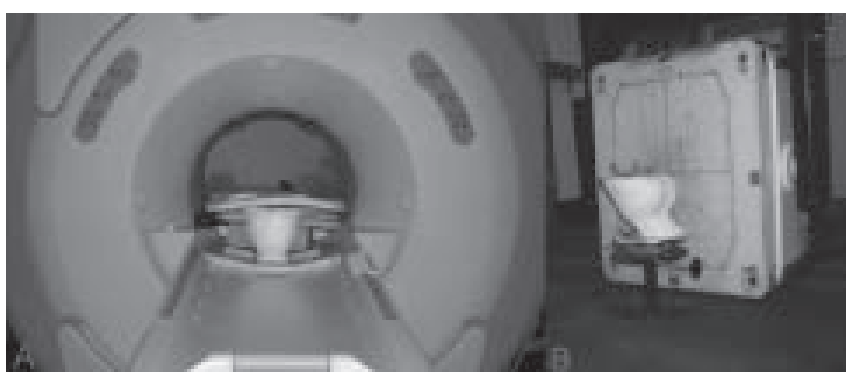

Fig 3 A-The model positioned in a torso phased-array human radiofrequency coil ready to undergo magnetic resonance imaging in a 1.5 Tesla GE MR Imaging system. B-The model positioned on a turntable ready to undergo scintigraphic examination.

A : Das Modell in einer Torso phased-array Radiofrequenz Spule aus der Humanmedizin vor der Magnetresonanztomographie in einem 1,5 Tesla GE MR Gerät. B: Das Modell positioniert auf einem Drehteller bereit für Szintigraphie.

\begin{tabular}{ccccccc}
\hline Table 1 & \multicolumn{7}{l}{ Magnetic resonance imaging parameters used to scan the foot phantom. } & & \\
\hline & Scan & TE & TR & Frequency & Phase & Slice thickness (mm) \\
\hline TIW SPGR & 3.7 & 8.9 & 256 & 256 & 3 & NEX \\
T2*W GRE & 3.7 & 10.1 & 256 & 256 & 3 \\
\hline
\end{tabular}

$\mathrm{TE}=$ echo delay time; TR = repetition time; $\mathrm{W}=$ weighted; SPGR = spoiled gradient echo; $\mathrm{GRE}=$ gradient echo; NEX = number of excitations 
Co-registration of MR and scintigraphic images with the Final Foot Phantom

The proprietary HERMES synchronisation and co-registration toolsh were used to co-register the anatomical MR volume image with the functional 3D SPECT volume image. The coregistration for this study was performed manually by a trained member of staff using overlaid fused images.

\section{Results}

The resolution of the reconstructed scintigraphic images was optimal for the 10 second per projection study reconstructed with resolution recovery, so all studies were acquired with this setting. These settings were verified by a trained member of staff.

In the MR images there was good resolution of the respective compartments of the phantom, and where simulated lesions with high signal intensity were located (Fig 4a, 5a).
MR image resolution was deemed adequate by two equine clinicians with extensive experience of diagnostic image evaluation. The anatomical resolution of the phantom scintigraphic images was less clear compared with images acquired clinically, likely related to the difference in phantom structure from clinical tissues, and because the normal structures are not visible (Fig 4b, 5b). However, the images acquired were deemed of adequate quality for the purpose of this study. This was the case with both injury combinations simulated in this study.

Image co-registration was successfully performed for both simulated injury combinations (Fig 4c, 5c). The localisation of the individual structures on co-registered images was much better than on the scintigraphic images alone, and the extent of areas of high radiopharmaceutical concentration was immediately apparent in the fused MR/scintigraphic image. Good alignment was observed between the anatomical compartments, ports and valves in the MR and scintigraphic images, supporting accurate co-registration.

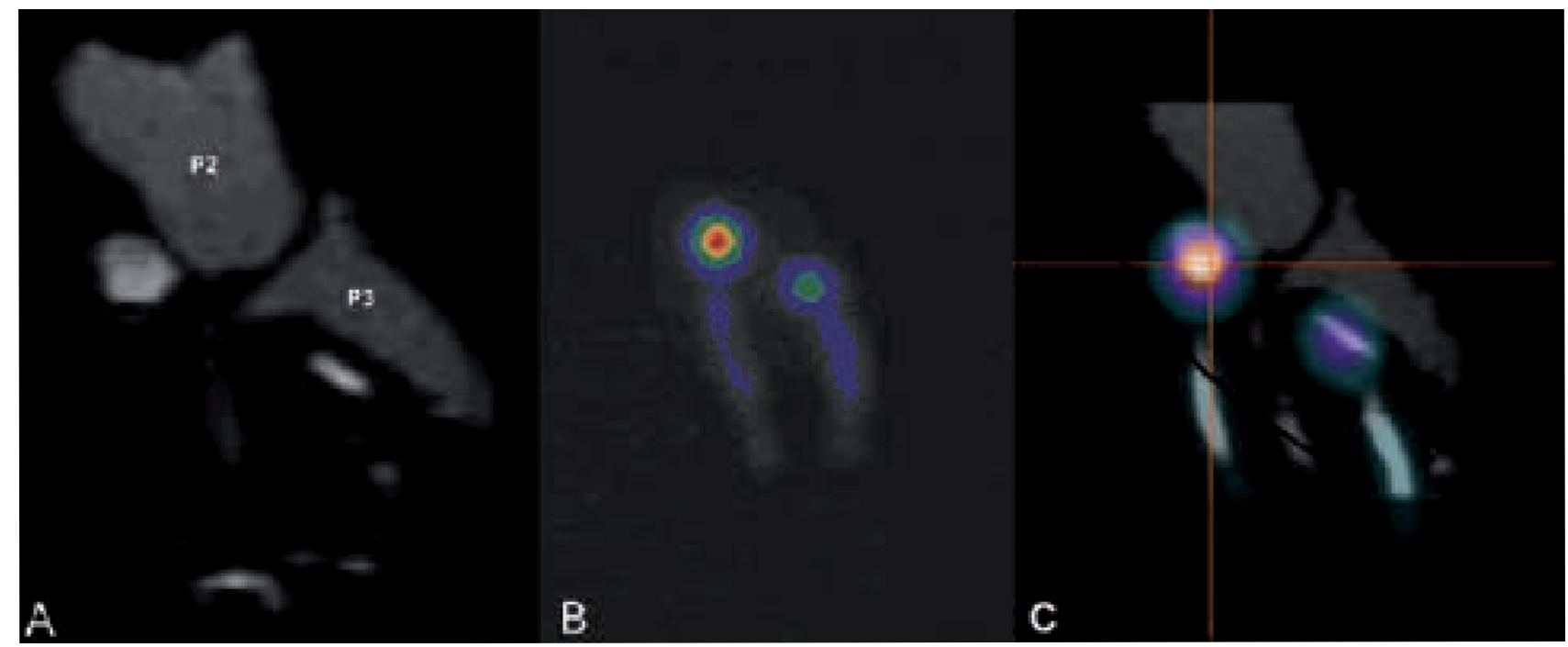

Fig 4 A-Sagittal 3D T1 weighted spoiled gradient echo magnetic resonance image, B-sagittal scintigraphic image and C-fused images of a simulated injury of the navicular bone and distal sesamoidean impar ligament in the equine foot model; dorsal to the left of the images. Notice all anatomical structures as visible on the MR image but only the simulated injury structures are visible on the scintigraphic image. P2 = middle phalanx; P3 = distal phalanx

A: Ein sagittales 3D Tl gewichtetes spoiled Gradientenecho MRT, B: sagittales Szintigraphie Bild und C: überlagerte Bilder einer simulierten Läsion des Strahlbeins und des Ligametum distale impar im Pferdefußmodell; dorsal ist links im Bild. Alle anatomischen Strukturen sind erkennbar auf den MRT Bildern während mit Szintigraphie nur die simuliente Läsionen dargestellt werden kann. P2 = mittlere Phalanx, P3 = distale Phalanx

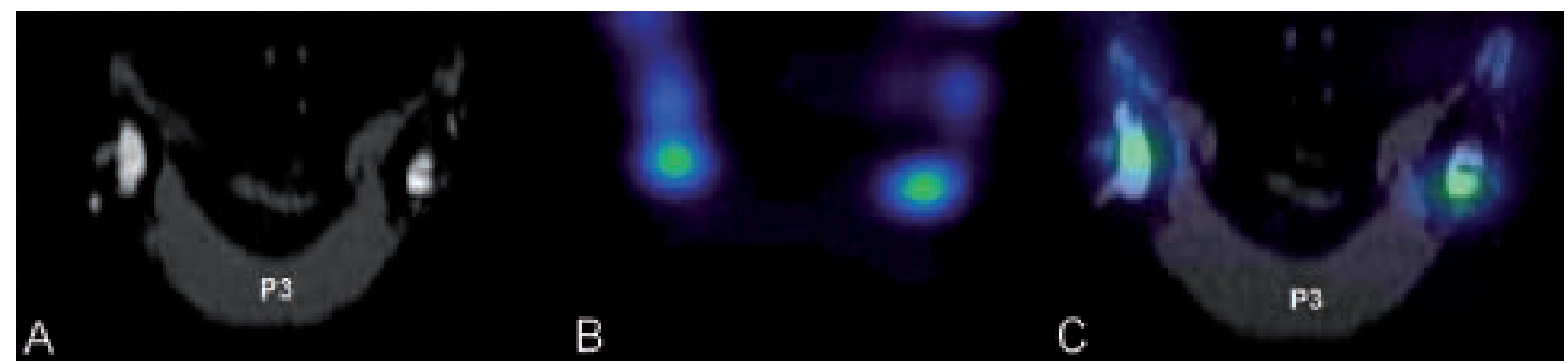

Fig 5 A-Transverse 3D T1 weighted spoiled gradient echo magnetic resonance image, B-transverse scintigraphic image and C-fused images of a simulated injury of the lateral palmar processes of the distal phalanx and the insertion sites of the medial and lateral collateral ligament of the distal interphalangeal joint on the distal phalanx in the equine foot model; dorsal is to the bottom of the images. Notice all anatomical structures are visible on the MR image, but only the simulated injury structures are visible on the scintigraphic image. P3 = distal phalanx A: Transverses 3D Tl gewichtetes spoiled Gradientecho MRT, B: transverses Szintigraphie Bild und C: überlagerte Bilder einer simulierten Läsion des lateralen Hufbeinastes und der Bandansätze des medialen und lateralen Seitenbandes des Hufgelenks im Pferdefußmodell; dorsal ist am unteren Ende des Bildes. Alle anatomischen Strukturen sind gut dargestellt mit MRT, während mit Szintigraphie nur die simulierte Läsion dargestellt werden kann. P3 = distale Phalanx 


\section{Discussion}

Although 3D MMI has, and is, being used in human medicine for the diagnosis of cancer and other ailments, this imaging technique requires validation in the horse prior to be being used in a clinical environment. The objective of this study was to develop and optimise methods for image co-registration using a bespoke equine foot phantom, and to assess the ability of 3D MMI to localise compartmentalised areas of high radiopharmaceutical concentration within specific regions of clinical significance. The results illustrate the increased precision that is possible when determining the localisation and extent of lesions within complex anatomy when comparing fused volumetric data to images from single imaging techniques. As with all the previous human studies (Pietrzyk et al. 1996, Kooy et al. 1997, Lattanzi et al. 1997, Fei et al. 2002, van Dalen et al. 2007, Giesel et al. 2009, Tsujikawa et al. 2010, Cho et al. 2011, Park et al. 2012), this study has shown that the technique could be applied to the equine foot, and the results indicate that it could further assist in determining the location of active injury.

The proprietary HERMES HybridRecon Advanced Reconstruction software corrects for the loss of resolution with distance observed with nuclear medicine collimation (Liu and Farncombe 2007). When assessed visually, the resolution of the 10 second per projection study, reconstructed with resolution recovery, was judged to be at least as good as that for the 30 second per projection study reconstructed with no resolution recovery. At 10 seconds per frame it would take only 20 minutes to acquire a $180^{\circ}$ study, comprising 120 projections, compared to an hour for 30 second projections. This resolution recovery technique may be important in a clinical environment because high-quality volumetric images would be acquired in as short a time as possible, which is essential when imaging a standing sedated horse.

The proprietary HERMES co-registration software can perform automatic co-registration provided there is sufficient anatomical similarity in the images. However, manual co-registration was needed in this particular study, because there was insufficient detectable similarity between the two image datasets. In real clinical cases it is to be expected that more anatomical information would to be available to make automated co-registration possible. The ports and feeds were used as landmarks to assist in this process. Scintigraphic images of the real equine foot show uptake in all structures of the foot, whereas the phantom only showed significant uptake in the simplified lesion structures. In most cases the additional anatomical information available in real, clinical scintigraphic images would provide sufficient anatomical information to allow fully automatic registration with MRI. A previous study has shown that automated co-registrations are more accurate than manual co-registrations (Sarkar et al. 2005). They also showed that the larger the structure, the smaller the error with co-registration and that automated co-registration required the least amount of user-time. Automated co-registration would be favourable in a clinical environment, because it is more accurate and faster than manual co-registration.

Rotary positron emission tomography (PET)/CT scanners have been successfully used for whole body scans on human cancer patients (Beyer et al. 2000, Shekhar et al. 2005) and a scanner has been developed for in-vivo imaging of small laboratory animals (Lage et al. 2008). In human patients using a combined scanner decreased the scan time by $40 \%$ and increased the accuracy of the co-registered images however further work is required to optimise this diagnostic tool for imaging small animals.

The advantages and limitations of a PET/CT and a SPECT/CT combination scanner compared with $\mathrm{MMI}$ using separate scanners have been discussed (Pfluger et al. 2004). The advantages of a combination scanner include one diagnostic imaging session, and hence less total time for diagnosis, and automatic fusion of images. The main limitations are the cost of the equipment, that staff require specialist training and that the diagnostic algorithms need to be optimised for each individual scanner. The advantages of $\mathrm{MMI}$ with separate scanners include: less costly than combination scanners, the ability to choose which imaging modality to use and the ability to select/alter the diagnostic algorithms. There are three main limitations which are: increased cost, increased total time for diagnostic imaging and that the patient may not be in exactly the same position for each modality (e.g. the patient might be at a slightly different angle.

Positioning a horse safely during image acquisition is a major consideration issue when considering scintigraphy. In addition, correct camera positioning is essential to achieve 2D scintigraphic images of high diagnostic quality. When imaging the equine foot, this necessitates either positioning the horse on a raised platform, or lowering the camera into a pit. This situation would indeed be further compounded when undertaking 3D imaging because the camera needs to be rotated around the patient to acquire the scintigraphic data. This would require design and construction of a special facility to ensure both safe positioning of the horse, correct alignment of the camera and to enable camera rotation.

There are 3 potential solutions to this problem: 1. create a platform with a gap between the limbs to allow the camera to rotate around a single limb; 2 . create a arced pit that would allow the camera to traverse around a single limb; or 3. utilise a human cardiac gamma camera that sits on 'train tracks' to go around the limb. However achieving either of these options, whilst ensuring patient, handler and equipment safety, is neither straight forward nor easy to implement effectively given the size of currently available cameras and the inherent difficulties in dealing with a quadruped anatomy. In essence, it is only realistic to envisage a situation where a camera could safely traverse $180^{\circ}$ around the outside of a limb without placing patient personnel and/or equipment at unacceptable risk. Nonetheless $180^{\circ}$ acquisition is acceptable for effective tomographic reconstruction in situations of low attenuation, which is the case when imaging the equine distal limb. Hence this may represent a clinically acceptable solution for the implementation of 3D imaging of a sedated standing horse.

\section{Limitations of the study}

The major limiting factor of this study was that an actual equine limb was not used. However, this study has proved the proof of principle evidence that 3D MMl works for the equine foot and that it provides images that could potentially assist in 
diagnostic assessment, however only two injury combinations were investigated due to faulty/leaking compartments within the phantom. The insertions sites of the DDFT and distal sesamoidean impar ligament were combined; in future studies these would be separated. Good alignment of the MR and scintigraphic images was seen; this supported the possibility of accurate manual co-registration because there was little anatomical similarity between the two sets of images. An artificial situation was created by scanning the phantom in a standing, weight-bearing position in MRI; in general practice this would not be the case but it was necessary to acquire images of high enough resolution. Our proof of principle study has shown that the co-registration of scintigraphic and MR images is possible and could in future be carried out with low-field standing MR images.

Future work is however required to overcome the technical difficulties in devising an image acquisition system capable of generating 3D scintigraphic images from live horses that can be co-registered with MR images obtained from existing standing MR technologies.

\section{Conclusions}

A method for image reconstruction and co-registration using an equine foot phantom has been developed. This unique and novel study, in equine veterinary diagnostic imaging, describes techniques that have shown that $3 \mathrm{D}$ co-registration of MR and scintigraphic data, obtained using practical acquisition times, does enhance the ability to detect and differentiate sites of high radiopharmaceutical concentration in the region of the distal interphalangeal joint and the palmar aspect of the distal phalanx. However, further investigation is required to validate the suitability of $3 \mathrm{D} M M \mathrm{MI}$ to investigate lameness/injuries in other locations within the foot, and also in other complex anatomical sites such as the metacarpo(tarso)phalangeal joints, the carpus and the tarsus. In the future, 3D co-registration of volumetric scintigraphic and MR images may prove clinically useful to enable differentiation between active and inactive injury.

\section{Acknowledgments}

Funding from Petplan Charitable Trust and De Montfort University, Leicester, and Julia Deutsch for her help with the German translation.

\section{Conflict of interest}

Steve Bloomer is the Director of Sales and Technical Services UK, and Susan Ellam is an Applications Physicist at Hermes Medical Solutions Ltd.

\section{Manufacturers' addresses}

Toshiba UK Imaging Systems Ltd., Chertsey, UK

Materialise $H Q$, Leuven, Belgium

MatWeb LLC, Blacksburg, Vancouver, USA

Laser Innovations, Santa Paula, California, USA
EOS GmbH, Munich, Germany

General Electric, Milwaukee, Wisconsin, USA

Bartec Technologies, Camberley, Surrey, UK

Hermes Medical Solutions, Stockholm, Sweden

\section{References}

Bailey R. E. A., Dyson S. J. and Parkin T. D. H. (2007) Focal increased radiopharmaceutical uptake in the dorsoproximal diaphyseal region of the equine proximal phalanx. Vet. Radiol. Ultrasound 48, 460-466

Barthez P. Y., Schaafsma I. A. and Pollak Y. W. E. A. (2006) Multimodality image fusion to facilitate anatomic localization of 99MTCPertechnetate uptake in the feline head. Vet. Radiol. Ultrasound 47, 503-506

Beyer T., Townsend D. W., Brun T., Kinahan P. E., Charron M., Roddy R., Jerin J., Young J., Byars L. and Nutt R. (2000) A combined PET/CT scanner for clinical oncology. J. Nucl. Med. 41, 1369-1379

Biggi M., Dyson S. J. and Murray R. C. (2009) Scintigraphic assessment of the metacarpophalangeal and metatarsophalangeal joints of horses with joint pain. Vet. Radiol. Ultrasound 50, 536-544

Cho Z., Son Y., Kim H., Choi E. J., Lee S. Y., CHI J. G., Park C. W., Kim Y. B. and Ogawa S. (2011) Observation of glucose metabolism in the thalamic nuclei by fusion PET/MRI. J. Nucl. Med. 52, 401-404

Collins S. N., Murray R. C., Kneiss/ S., Stanek C. and Hinterhofer C. (2009) Thirty-two component finite element models of a horse and donkey digit. Equine vet. J. 41, 219-24.

Dyson S. (2002) Subjective and quantitative scintigraphic assessment of the equine foot and its relationship with foot pain. Equine vet. J. 34, 164-170

Dyson S., Murray R., Schramme M. and Branch M. (2003) Magnetic resonance imaging of the equine foot: 15 horses. Equine vet. J. $35,18-26$

Dyson S., Murray R., Branch M., Whitton C., Donovan T. and Harding E. (2003) The sacroiliac joints: evaluation using nuclear scintigraphy. Part 1: the normal horse. Equine vet. J. 35, 226-232

Dyson S., Murray R., Schramme M. and Branch M. (2004) Collateral desmitis of the distal interphalangeal joint in 18 horses (2001 2002). Equine Vet. J. 36,160-166

Dyson S., Murray R. and Weekes J. (2006) Scintigraphic evaluation of the proximal metacarpal and metatarsal regions in horses with proximal suspensory desmitis. Vet. Radiol. Ultrasound 48, 78-85

Dyson S. J. and Murray R. C. (2007a) Verification of scintigraphic imaging for injury diagnosis in 264 horses with foot pain. Equine vet. J. 39, 350-355

Dyson S. J. and Murray R. C. (2007b) Use of concurrent scintigraphic and magnetic resonance imaging evaluation to improve understanding of the pathogenesis of injury of the podotrochlear apparatus. Equine vet. J. 39, 365-369

Dyson S., Nagy A. and Murray R. (2011) Clinical and diagnostic imaging findings in horses with subchondral bone trauma of the sagittal groove of the proximal phalanx. Vet. Radiol. Ultrasound $52,596-604$

Dyson S. (2011) The Foot and Pastern: Adult Horse. IN: Equine MRI. Ed: Murray, R. 1st ed. Wiley-Blackwell, Oxford, p.149-166.

Dyson S. and Murray R. (2011) The Foot and Pastern. IN: Equine MRI. Ed: Murray, R. 1st ed. Wiley-Blackwell, Oxford, p.271-314

Dyson S. J. (2012) Primary lesions of the deep digital flexor tendon within the hoof capsule. IN: Diagnosis and management of lameness in the horse 2nd edition, Ed: Ross M. W. and Dyson S. J., Elsevier Saunders, Missouri, p.344-348

Fei B., Duerk J. and Wilson D. (2002) Automatic 3D registration for interventional MRI-guided treatment of prostate cancer. Comput. Aided Surg. 7, 257-267

Giesel F. L., Mehndiratta A., Locklin J., McAuliffe M. J., White S., Choyke P. L., Knopp M. V., Wood B. J., Haberkorn U. and von Tengg-Kobligk H. (2009) Image fusion using CT, MRI and PET for treatment planning, navigation and follow up in percutaneous RFA. Experiment. Oncol. 31, 106-114 
Gonzalez L. M., Schramme M. C., Robertson I. D., Thrall D. E. and Redding R. W. (2010) MRI features of metacarpo(tarso)phalageal region lameness in 40 horses. Vet. Radiol. Ultrasound 51, 404414

Henriksen O. M., Lonsdale M. N., Jensen T. D., Weikop K. L., Holm O., Duss B. and Friberg L. (2009) Two-dimensional image fusion of planar bone scintigraphy and radiographs in patients with clinical scaphoid fracture: an imaging study. Acta Radiol 50, 71-77

Hopkinson N., Hague R. and Dickens P. (2006) Introduction to Rapid Manufacturing. IN: Rapid Manufacturing: An Industrial Revolution for the Digital Age. Ed: N. Hopkinson, R. Hague and P. Dickens, John Wiley \& Sons Ltd, Chichester; p. 1-4

Kooy H. M., van Herk M., Barnes P. D., Alexander E. 3rd, Dunbar S. F., Tarbell N. J., Mulkern R. V., Holupka E. J. and Loeffler J. S. (1997) Image fusions for steretactic radiotherapy and radiosurgery treatment planning. Int. J. Radiat. Oncol. Biol. Phys. 28, 12291234

Lage E., Vaquero J. J., Sisniega A., Espana S., Tapias G., Udias A., Garcia V., Rodriguez-Ruano A. and Desco M. (2008) VrPET/CT: Development of a rotating multimodality scanner for small-animal imaging. IEEE Nuclear Science Symposium Conference Record, 4671-4674

Lattanzi J. P., Fein D. A., McNeeley S. W., Shaer A. H., Movsas B. and Hanks G. E. (1997) Computed tomography-magnetic resonance imag fusion: a clinical evaluation of an innovative approach for improved tumor localization in primary central nervous lesions. Radiat. Oncol. Invest. 5, 195-202

Liv S. and Farncombe T. H. (2007) Collimator-Detector Response Compensation in Quantitative SPECT Reconstruction. IEEE Nuclear Science Symposium Conference Record, 3955-3960

Murray R. C., Schramme M. C., Dyson S. J., Branch M. V. and Blunden T. S. (2006) Magnetic resonance imaging characteristics of the foot in horses with palmar foot pain and control horses. Vet. Radiol. Ultrasound 471 1-16

Murray R. and Werpy N. (2011) Image interpretation and artefacts. IN: Equine MRI, Ed: Murray RC, Wiley-Blackwell, p.101-145

Nagy A., Dyson S. J. and Murray R. C. (2008) Radiographic, scintigraphic and magnetic resonance imaging findings in the palmar processes of the distal phalanx. Equine vet. J. 40, 57-63

Park H., Wood D., Hussain H., Meyer C. R., Shah R. B., Johnson T. D., Chenevert T. and Piert M. (2012) Introducing parametric fusion PET/MRI of primary prostate cancer. J. Nucl. Med. 53, 546-551

Pfluger T., la Fougere C., Stauss J., Santos R., Vollmar C. and Hahn K. (2004) Kombinierte Hybridsysteme (PET/CT, SPECT/CT) versus multimodale Bildgebung mit getrennten Systemen. Radiologe 44, $1105-1121$

Pietrzyk U., Herholz K., Schuster A., von Stockhausen H.-M., Lucht H. and Heiss W.-D. (1996) Clinical applications of registration and fusion of multimodality brain images from PET, SPECT, CT and MRI. Eur. J. Radiol. 21, 174-182

Rabba S., Bolen G., Verwilghen D., Salciccia A. and Busoni V. (2011) Ultrasonographic findings in horses with foot pain but without radiographically detectable osseous abnormalities. Vet. Radiol. Ultrasound 52, 95-102
Rueckert D. and Schnabel J. A. (2011) Medical Image Registration. IN: Biomedical Image Processing. Ed: Deserno T. M. Springer-Verlag Berlin Heidelberg, p.131-154

Sarkar A., Santiago R. J., Smith R. and Kassaee A. (2005) Comparison of manual vs. automated multimodality (CT-MRI) image registration for brain tumors. Med. Dosim. 30, 20-24

Shekhar R., Walimbe V., Raja S., Zagrodsky V., Kanvinde M., Wu G. and Bybel B. (2005) Automated 3-dimensional elastic registration of whole-body PET and CT from separate or combined scanners. J. Nucl. Med. 46, 1488-1496

Sherlock C. E., Kinns J. and Mair T. S. (2007) Evaluation of foot pain in the standing horse by magnetic resonance imaging. Vet. Rec. $161,739-744$

Simon V. and Dyson S. J. (2012) Radiographic and scintigraphic evaluation of the third carpal bone of control horses and horses with carpal lameness. Vet. Radiol. Ultrasound 53, 465-473

Slomka P. J. and Baum R. P. (2009) Multimodality image registration with software: state-of-the-art. Eur J Nucl Med Mol Imaging, 36: 44-55

Tsujikawa T., Kabibayashi T., Tsuchida T., Ohkoshi Y. and Kimura H. (2010) Embolic infarction followed by serial bone SPECT and MR fusion images - the door to SPECT/MR. J. Med. Inves. 57, 334337

van Dalen J. A., Vogel W. V., Corstens F. H. M. and Oyen W. J. G. (2007) Multi-modality nuclear medicine imaging: artefacts, pitfalls and recommendations. Cancer Imaging 7, 77-83

van der Born M. J., Pluim J. P. W., van de Kraats E. B., Sprinkhuizen S. M., Timmer J., Homan R. and Bartels L. W. (2011) Registration of 2D x-ray images to 3D MRI by generating pseudo-CT data. Phys. Med. Biol. 56, 1031-1043

Weekes J. S., Murray R. C. and Dyson S. J. (2006) Scintigraphic evaluation of the proximal metacarpal and metatarsal regions in clinically sound horses. Vet. Radiol. Ultrasound 47, 409-416

Wohlers T. (2009) Wohlers report 2009: State of the Industry: Annual Worldwide Progress Report. 2009, Wohlers Associates Inc.

Carolyne Tranquille, BSC.

Equine Orthopaedic Research Assistant

Centre for Equine Studies

Animal Health Trust

Lanwades Park

Newmarket

Suffolk CB8 7UU

England

carolyne.tranquille@aht.org.uk 